\title{
SIMULATION OF BRIDGE CONSTRUCTION WORKS: AN EXPLORATORY STUDY
}

\author{
FAHIMEH ZAERI and JAMES OLABODE BAMIDELE ROTIMI
}

Construction Management Programme, Auckland University of Technology, New Zealand.

\begin{abstract}
Bridge construction projects are associated with uncertainties partly due to sequencing issues, logistics, interactions, and resource constraints. Their construction is mostly cyclic and repetitive, yet complex, requiring innovative approaches to cope with its management. Construction projects planners seek methods to enable them to schedule bridge construction projects in consideration of these constraining factors. The main objective of this research is to develop a concept of a simulation-based modeling approach. It aimed to decide which data in real systems are important for the modeling of an operation, and in which way they must be gathered to help planners approach a proper simulation-based schedule. A case study project based in New Zealand was selected for this paper. It focuses on developing a resource-based model of bridge construction using a launching-girder construction method, taking into account the complex interactions among the project's components. The discrete elements within the project and steps taken to develop a model are described in this paper. The study enhances knowledge on the applicability of simulation in repetitive construction operation, which in turn can provide more realistic models for scheduling progress.
\end{abstract}

Keywords: Simulation, Repetitive, Complexity, Interdependency, Scheduling, Bridge construction.

\section{INTRODUCTION}

Construction projects or operations are a collection of activities that are linked together through resources, which are used for their accomplishment according to their logical sequence (Halpin \& Riggs 1992). These series of activities make a chain that defines a project's activity cycle. According to Shi (1997), the cycle could either be a closed or open loop, with complex interdependencies of resources consumed by the project. The task of every project manager is to plan for the use of resources in a manner that supports the logical sequences required of construction operations. This task is made cumbersome by the complexity and dynamic characteristics of construction projects, with Halpin and Riggs (ibid) suggesting that the planning function is crucial, knowledge-intensive, often ill-structured, presenting a challenging stage in every development project.

Interactions within construction projects are inherently complex, and very often do not allow construction managers to accurately evaluate the final effects of the relationships between operational parameters on project durations using conventional decision making tools (Alvanchi 2011). In addition, creating a feasible project schedule that will allow balanced achievements of overall project objectives (e.g., time, cost and 
quality) would seem elusive with conventional planning tools. This performance aspect is a major concern in the construction project domain (Srisuwanrat 2009). Wu et al. (2009) suggest these challenges are the main drivers for computer-based solutions that could speed up and improve project scheduling. More modern tools tend to capture human knowledge and experiences in the form of a set of data and rules, which are then processed by computers.

In bridge construction projects (BCP), the planning and analysis function is even more complex, because such projects are associated with uncertainties arising from their construction sequence, as well as associated constraints, resourcing issues, and structural adequacies (Chan \& Lu 2012). Hohmann (1997) (as cited in Ailland et al. 2010) contends that factors such as changing boundary conditions, project time and costs pressures, difficult logistic requirements, and the probability of unexpected incidents are common to non-stationary construction processes like bridge works. Therefore, planners would need to employ scheduling techniques that could give more effiicient control and guidance on the use of resources. Ailland et al. (2010) conclude that planning methods that feature adequate adaptability, support the description of parallel processes, and take into account unexpected incidents and stochastic and fuzzy parameters are therefore to be encouraged for non-stationary construction projects.

Computer-based techniques or simulation methods/tools have been effective in the design, planning and analysis of construction projects regardless of complexity or size (AbouRizk 2010). Halpin (1977) made it clear that when repetition is evident, simulation modelling becomes the preferred method for representing repetitive tasks included in cyclic networks and linear projects. According to AbouRizk (ibid), linear repetitive projects (like bridge construction projects) provide opportunities for performing comprehensive analysis using techniques such as simulation for productivity improvement.

A host of simulation-based techniques for scheduling construction projects are in use. Some are specific to the construction industry, while others have been developed to deal with specific conditions like repetitive or cyclic performances. The selection of an appropriate simulation tool requires prior understanding and analysis of a construction project.

In this study, we investigate possible improvements to existing scheduling methods for a bridge construction project based in Auckland, New Zealand. The study takes into account constraints/uncertainties and complex interactions among the bridge project's components, with the aim of developing a simulation model for the project. The field investigation is described below to demonstrate the capabilities of simulations in the scheduling of repetitive bridge construction projects.

\section{DESCRIPTION OF THE CASE STUDY}

The construction of bridges along road ramps on the project uses self-launching Twin Truss Gantry as the construction method for the erection. The construction of the ramps comprises a series of repetitive activities and sub-activities in a cycle.

\section{STUDY METHOD}

Literature on construction simulation models have been mainly employed at the early stages of planning and design, since they are built on rigid assumptions and design 
parameters like activity durations, and sequence logic. However, Akhavian and Behzadan (2013) explained that generating simulation models responsive to real-time changes within the execution phase is challenging. This underlines the importance of a robust methodology that supports the collection and processing of field data, and the effective extraction of relevant contextual knowledge about a project. In line with this, a Discrete Event-based Simulation (DES) has attracted attention, used by planners to model interactions among resources and operational logic. To apply DES, some basic steps need to be accomplished in line with Al-Ghtani (undated): 1) define resources, 2) identify work tasks in process (work tasks with which resources are involved), 3) determine the logic of processing of resources, and 4) build a model of the process.

Our fieldwork investigates the applicability of simulation for launching bridge girders using a twin truss gantry between piers and abutments. Information was gathered on operations and associated activities in the erection of bridge girders along a road ramp. The erection began at the South abutment and moved North using 70-ton gantry cranes. The gantry crane worked with different span lengths according to the beam design (in this case, span lengths averaged $31.50 \mathrm{~m}$ ). When a bridge span was completely erected, the launching gantry self-launched to the subsequent pier, and the entire process was repeated for the next span girder. The ramp involved the construction of 7 spans with 6 intermediate piers. This translated to 7 process cycles for the erection of the girders. In the following sections the steps described give an indication of simulation model development considering resource interactions and repetitive behavior.

\subsection{Identifying Activities}

The first activity in the simulation model development process identifies the operations, and activities/sub-activities involved. Then there was a study of the construction execution plan for other ancillary activities, such as gantry assembly and gantry plinth construction. Both are preliminary work required before the Super T-beam erection. Other sub-activities are presented in Appendix A.

The main focus of this study was beam launching and erection using a twin-truss gantry. Monitoring of this section started in early 2014 after beginning construction of the first ramp. The data required to understand system behavior have been taken into account by data collection and construction of a conceptual model (see Figure 1).

\begin{tabular}{cl}
\hline Data & \multicolumn{1}{c}{ Description of data } \\
\hline Number of crews & How many team works involved in project? How many persons includad in each team? \\
machines/equipment & Information including machines and equipment are required for modelling resource flow \\
\hline Work Hours & Operation hours are important for duration estimation \\
\hline Span/Beam Number & Span number would be referred in any construction execution method \\
\hline Types of supports & Construction methods depend on types of support: a) two piers b) pier and abutment. \\
\hline Conditions of the spen & You may nesd night shift becsuse of closure of road lane when the span cross over the existence road \\
\hline Numbers of beam included in each span & This information is important in the case of sequence of placement of Super T beams \\
\hline Length of beam & Depends on the length of beam, the position of winches need to be changed \\
\hline Placement types & Temporary/Permanent \\
\hline Types of beam & Based on its position in span: Edge/ Mid beam \\
\hline Types of Curve shape on Edge beam & $\begin{array}{c}\text { The delivery and hooking super T beam to the trusses becomes different depends on the types of } \\
\text { curve }\end{array}$ \\
\hline
\end{tabular}

Figure 1. Detail information of project (modelling input data) 
Next, the activities involved in the self-launching progress and erection performances were recorded. The first operation in terms of delivery of Super T-beam is represented in Appendix B.

\subsection{Identifying Resources (Flow Unit)}

Resources are the driving force in construction operations. An activity always consumes time and resources. A resource can supply either one single activity or a series of activities, and it should be assigned before the activity starts and be released after its relevant task is complete (Shi 1997). For example, the main resources engaged within this project included a trailer and jinker, crane, gantry crane, lifter, merlo, tandano crane, cherry picker, auxiliary support, erection beam support, bogie, rollers, master, slave winches, etc.

\subsection{Identifying the States}

Identifying the state of engaged resources is introduced as a main step to extract basic knowledge about a resource (Akhavian \& Behzadan 2013). Moreover, Halpin and Riggs (1992) proposed that 1) the identification of major resources, 2) establishing the various states, and 3) having the resources traverse in their work assignment paths and cycles, are important steps to develop the skeletal framework of a construction operation. Another effective factor in modelling the construction operation, at the stage of developing Flow Unit Cycles, is the selection of suitable task modelling elements. This in turn enables the model to present the construction technology and methods engaged in the construction operation (Halpin \& Riggs 1992).

The elements selected to represent resource states in this research follow Halpin's modelling elements, basically categorized as four types: Q, Fusion, Normal, and Arrow (see Appendix C). Using these elements, the Beam Erection Operation is charted to illustrate the interaction among resources and activities as well as performance sequences (see Appendix D).

The erection operations begin with beam delivery. The cycle starts from the arrival of precast Super T-beam on trailer \& jinker truck. The truck travels to the main truss of the gantry crane. The truck waits for the gantry crew to restrain the strand anchors on the Super T-beam. The winches move towards auxiliary support and the lifting block moves down to be fixed on the top of the beam. The beam is then lifted up to the main trusses. The unloaded truck then leaves the gantry area. The T-beam is then placed on the ground while some preprations prior to erection (e.g., installing clamps guide, and walking platform) are made. The beam is then hooked up by lifting blocks and loaded to the main trusses. This cycle is repeated for each new beam that arrives with the trucks. The performance sequences and required materials may be different for individual T-beams (in terms of position, edge or intermediate beams; shape, convex or concave; and length).

\section{CONCLUSIONS}

This paper presents a conceptual framework for analyzing and modelling a bridge construction operation using a self-launching method. The framework embedded the crucial steps and criteria in application of modelling methods on bridge construction 
projects. It assisted in developing resource-based model for typical repetitive project as well as providing operational knowledge in bridge projects simulation. The approach in this study provides opportunities for future researches to investigate which simulation tool(s) could be appropriate for taking system behavior (i.e., repetitive, dynamic, and uncertain nature) into account.

\section{Appendix A. Activities involved in Preliminary Works}
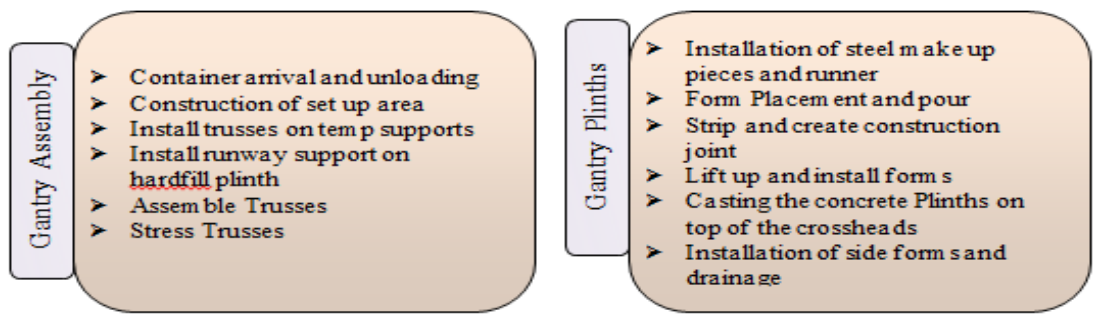

\section{Appendix B. Activities involved in Beam Delivery Operation}

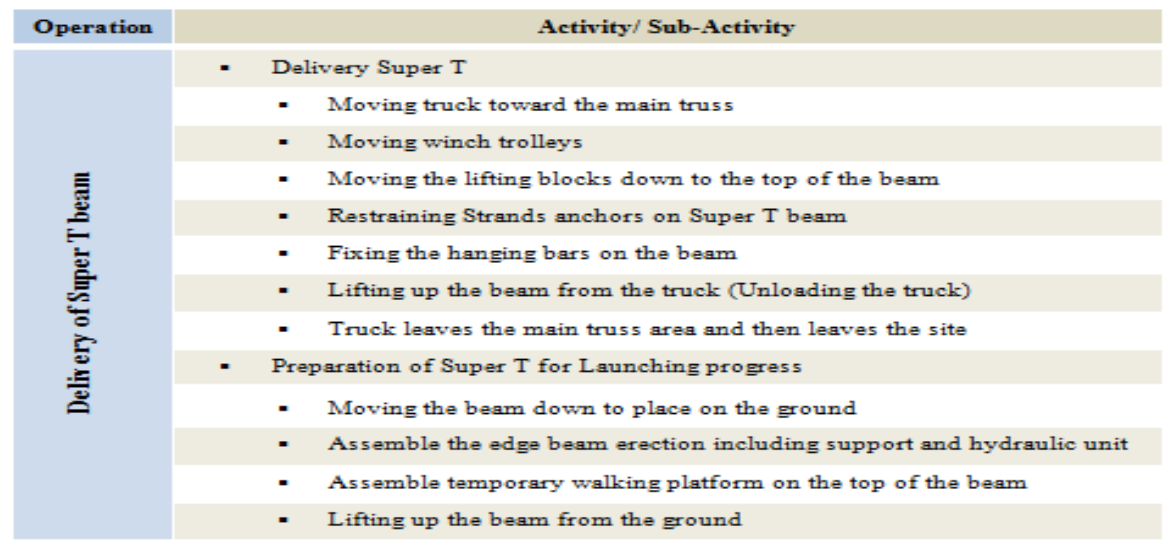

\section{Appendix C. Modelling Element}

\begin{tabular}{ccc}
\hline Modelling Element & Name of Element & Description of Modelling Element \\
\hline & Active & $\begin{array}{c}\text { Represents the Idle state of the resource while it waits to be } \\
\text { used by subsequent resource }\end{array}$ \\
Fusion & $\begin{array}{c}\text { Represents the resource that it will be procest when all its } \\
\text { requirements are available. }\end{array}$ \\
Arrow & Represents the direction of resource entity flow:
\end{tabular}




\section{Appendix D. Flow Units Diagram of a Beam Delivery Operation}

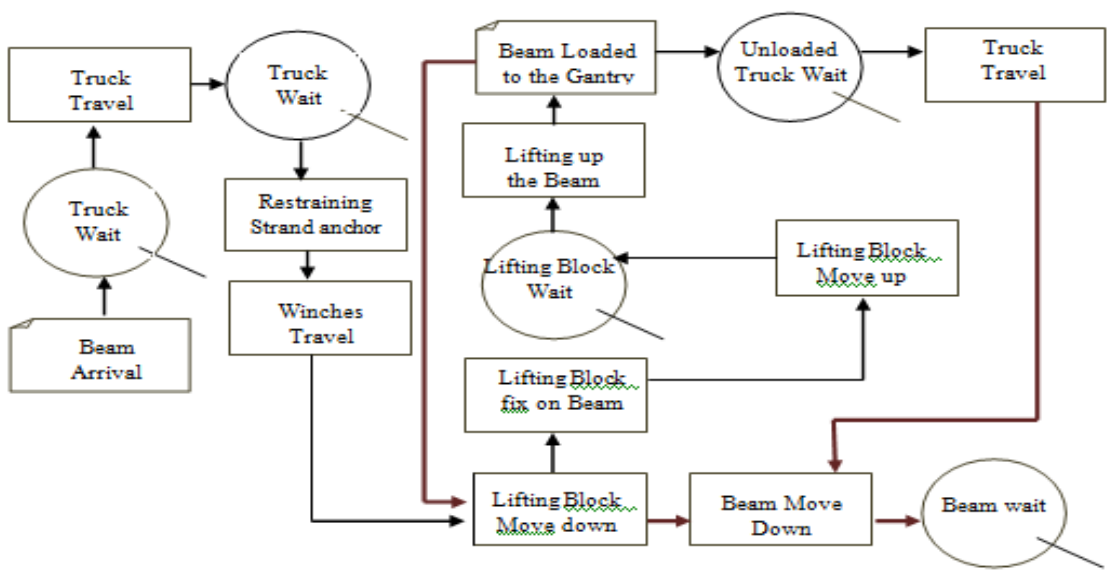

\section{References}

AbouRizk, S., Role of Simulation in Construction Engineering and Management, Journal of Construction Engineering and Management, 136(10), 1140-1153, 2010.

Ailland, K., Bargstädt, H. J., and Hollermann, S.. Construction process simulation in bridge building based on significant day-to-day data, Winter Simulation Conference. Symposium conducted at the meeting of the Proceedings of the Winter Simulation Conference, 2010.

Akhavian, R., and Behzadan, A. H., Knowledge-Based Simulation Modeling of Construction Fleet Operations Using Multimodal-Process Data Mining. Journal of Construction Engineering and Management, 139(11), 2013.

Al-Ghtani, K., Application of Simulation in Construction Processes (Planning and Modeling of Construction). In E. C. King Saud University, Civil Engineering Department (Ed.), undated..

Alvanchi, A., Incorporating the Effects of Complex Dynamic Interactions in the Construction Decision Making Process, ProQuest, UMI Dissertations Publishing, 2011.

Chan, W. H., and Lu, M., Construction operations simulation under structural adequacy constraints: the Stonecutters Bridge case study, IEEE Symposium conducted at the meeting of the Simulation Conference (WSC), Winter, 2012.

Halpin, D. W., CYCLONE-method for modeling job site processes, Journal of the Construction Division, 103 (ASCE 13234 Proceedings), 1977.

Halpin, D. W., and Riggs, L. S., Planning and Analysis of Construction Operations, John Wiley and Sons, Inc., New York, N.Y., 381, 1992.

Hohmann, G., Von der Netzplantechnik zur Simulation-Analyse von Bauprozessen mit Hilfe von Petri-Netzen, 1997.

Shi, J., A conceptual activity cycle-based simulation modeling method, IEEE Computer Society, 1997.

Srisuwanrat, C., The Sequence Step Algorithm: A simulation-based scheduling algorithm for repetitive projects with probabilistic activity durations, ProQuest,UMI Dissertations Publishing, 2009.

Wu, I., Borrmann, A., Rank, E., Beißert, U., and König, M, A pattern-based approach for facilitating schedule generation and cost analysis in bridge construction projects Symposium conducted at the meeting of the Proc. of the 26th CIB-W78 Conference on Managing IT in Construction, 2009. 